\title{
A Study of the Effects of Time Pressure on Translation Quantity and Quality
}

\author{
Mehdi Ghobadi (Corresponding author) \\ Institute for Humanities and Cultural Studies, Iran \\ Email: mehdi.ghobadi64@gmail.com \\ Golnaz Madadi \\ Islamic Azad University South Tehran Branch, Iran \\ Bahareh Najafian \\ Islamic Azad University South Tehran Branch, Iran
}

Received: 04-02-2017

doi:10.7575/aiac.ijclts.v.5n.2p.7
Accepted: 19-03-2017

Published: 30-04-2017

\begin{abstract}
The condition under which translation is undertaken has been the subject of little empirical research. The present study aimed to determine whether time pressure would have influential effects on the quality and quantity of a translation task performed by Iranian students of Translation Studies. For this purpose, the students in two intact MA translation classrooms were selected as the participants of the study; i.e., one control group and one experimental group. The participants in the control group were allowed as much as time they needed to perform the translation task whereas the participants in the experimental group were allowed only 30 minutes to perform the task. The results of the study indicated that time pressure had significant influences on both the quality and quantity of the translation task performed by the participants. A trade-off was observed as the participants in the experimental group produced more translated materials than the participants in the control group when compared on a time-constant scale. The quality of their performance, however, lagged behind the quality of performance by the participants in the control group. These results can be explained by the competition model of cognition which hypothesizes that different dimensions of a cognitive task are in constant competition to win over attentional resources and that the competition is highly influenced by the condition in which the task is performed. The implications of the study for both translation theory and practice are also discussed.
\end{abstract}

Keywords: Time Pressure, Cognitive Sciences, Translation Quantity, Translation Quality, Attentional Resources

\section{Introduction}

Corpus studies have been the major trend in the field of language studies. This is not surprising because translation is mainly about rendering the meaning of a text, which is a type of corpus, from a language (i.e., source language/SL) into another language (target language/TL). In addition, these studies have dealt with something that is concrete and observable to the researcher; i.e., the TL text which is the product of a translation undertaking. However, in the last two decades, researchers have come to the recognition that translator-internal factors also play a significant role on the quality with which translators can deliver translation outputs (e.g., Danks, 1997; Halverson, 2003; Shreve \& Angelone, 2010; Xuanmin, 2003). More particularly these researchers contend that cognition (i.e., mind) and its antecedents are the most important determinants of translation success because cognition is the place where the translator makes decisions as to what translation strategies to use to address translation challenges, how to monitor translation performance, and how to assess the quality of translation performance. Further, these researchers argue that the role of cognition in translation success is mediated by the characteristic features of the context under which a translation task is undertaken. This latter line of research new in the field of Translation studies and there remains a lot to unearth.

The purpose of investigation followed in this study is to examine time conditions under which translators render a text from the SL into the TL. Conditions of translation highly affect the quality with which translators can translate the SL text. However, less is known about the effects that time conditions have on the quantity and quality of translation attempts. This is unfortunate because translation market is under pressure to identify and employ translators who are able to deliver translation products with high qualities as fast as possible (see Choi \& Lim, 2000; Hermans \& Lambert, 1998; Ørsted, 2001).

As mentioned above, translation from a language into the other requires the involvement of the translator's mental resources (Bassnett, 2013; Gutt, 2014; O'Brien, 2013). Such a view of translation urges us to consider translation as a 'cognitive task', with the implication that we should move beyond examining the textual features of translation products towards investigating the strategic decisions that the translator has to make to address the challenges he/she face during the process of translation. In the following paragraphs, a literature review of the cognitive approaches to Translation 
Studies is presented. It is argued that cognitive sciences have a lot to offer to both translation theory and research. Further, a firm ground is set as to why translation researchers need to focus their attention on the conditions under which translation task are performed as these conditions highly affect the translator's success to render the assigned text from the SL into the TL with high quality.

\section{Cognitive Sciences and Translation Processes}

Cognitive sciences are a subfield of psychology and education that considers the human being as a 'thinking' entity. In other words, according to cognitive psychologists, a person forms mental rules in his own mind based on the output they receive from the surrounding environment (Brown, 2006; Eysenck \& Keane, 2000). These rules are then applied to the new learning and behavior situations that arise in the person's life. This idea is in contrast to the behavioristic conceptions of human behaviors and learning which assert that people learn new behaviors through the association they make between stimuli and corresponding responses (Ertmer \& Newby, 1993). Cognitive psychologists, however, harshly rejected this idea. For example, in the realm of language knowledge, Chomsky (1965) argued that the stimulusresponse association cannot explain language knowledge efficiently. In the realm of mental disorder, cognitive psychologists believe that pathological human behaviors (e.g., anxiety, narcissism, border-line personality disorder, etc.) are not the results of what in behaviorism is called 'conditioning' (i.e., elicitation of particular behaviors by presenting particular stimuli). Rather, these malfunctioning behaviors are the results of distorted images that people form in their minds about the outside world and their own role in it (Brown, 2006). The implication of this argument for treating people with mental disorders is that therapists should try to help people with mental disorders get rid of mistaken schemata they have about themselves and the outside world. In the realm of education, the more accepted belief is that learning would be more effective when the learner is able to associate new learning materials with previously existing structures in his/her mind. The implication is that what is presented in the classroom should be related to the learner's personal life and cognitive development (Ausubel, 1960; Novak, 2010).

According to above lines, it would not raise so much criticism to claim that cognitive sciences have influenced all fields of study in Humanities and Social Sciences. The field of Translation Studies, however, has benefited less from cognitive sciences. This can be explained by the fact that the field of Translation Studies have particularly preoccupied itself with corpus-based studies the aim of which have been to determine how textual features are rendered from the SL into the TL in different types of genres (for a review of this approach to Translation Studies, see Kuhiwczak \& Littau, 2007; Munday, 2016). Fortunately, in recent decades, translation researchers have become aware that cognitive sciences have a lot to offer to the field of Translation Studies (Gutt, 2014; O'Brien, 2013). They now believe that translation is "an 'expert task' requiring specific competences, all of which have to be strategically managed to reach a successful outcome" (O'Brien, 2013, p. 8, emphasis is added). The idea of translation as a cognitive task has driven researchers to launch studies to investigate variables that may affect translation task performance. These studies have followed one of two trends. They have either showed interests in examining what effects differences between translators have on their success to translate an SL text into the TL (e.g., Hubscher-Davidson, 2009; Zheng \& Xiang, 2014). Or, they have investigated what goes on in the translator's mind when he embarks on translating an SL text into the TL (O'Brien, 2013). Less is known about the conditions under which translation is undertaken. So, the present study was set to examine the effects of one of these conditions on translation task performance (i.e., time pressure). In the following paragraphs, an overview of the effects of time pressure on cognitive task performance is presented as a ground for understanding the purposes of the present study.

\section{Time and Task Performance}

The conditions under which a task is performed highly influence the person's ability to perform the task. Literature on industrial psychology and cognitive sciences has seen an abundant interest in examining what effects conditions have on work and cognitive task performance (e.g., Eysenck, \& Calvo, 1992; Kahn, 1990; Saks, 2006; Shao, Roelofs, Martin, \& Meyer, 2015). Studies have been carried out to investigate the effects of such variables as anxiety, music, interruption, annoyance, technology, etc. on the person's ability to perform task. In this research area, one of the variables that have appealed to researchers in the field of cognitive sciences is 'time'. According to both industrial and cognitive psychologists (e.g., Harrison, Price, Gavin, \& Florey, 2002; Labelle, Graf, Grondin, \& Gagne-Roy, 2009), task performance success is in part determined by the time allowed to individuals to perform the task.

In the field of cognitive sciences, there are two arguments for explaining why time pressure may affect task performance. The first argument is that time pressure raises a person's anxiety levels and, therefore, disrupts his ability by introducing factors to his mental resources that may be unrelated to the cognitive task to be performed. In fact, there is a bulk of evidence to believe that task anxiety is raised when a person is required to perform the task under time pressure (Eysenck, \& Calvo, 1992; Eysenck \& Keane, 2000; Guida, Ludlow, \& Wilson, 1985). The second argument, on the other hand, discusses that time pressure does not negatively affect the whole task performance; rather, it affects the allocation of attentional resources to different aspects of task performance. In other words, under undesirable task performance conditions, different aspects of a task try to win over attentional resources, a situation which results in a trade-off between these aspects. This second argument is known as the competition model of human cognition which contends that different stimuli in the surrounding environment are in a constant competition to allocate a person's processing capacities to themselves (Ellis, 2006; Potter, Staub, \& O'connor, 2002). Similarly, when a person is performing a cognitive task (e.g., taking in a second language, studying with music in background, etc.), the different aspects of the task will do their best to win over the persons' attentional resources. For example, when the person embarks on taking a second language, particularly if his/her proficiency in the second language is not at advanced 
levels, there would be a tradeoff between attention resources allocated to the meaning of the utterances versus the grammaticality of the utterances. The situation becomes more complex when we come to know that meaning and grammar can compete with how fluently the person can talk in the second language in online second language communication situations (see Mehnert, 1998; Boxer \& Cohen, 2004). In a similar vein, a student's attention may be distracted when he tries to study for the school by such factors as background music, noise in the environment, thinking about memories, etc.

As mentioned earlier, the purpose of the present study is to see whether conditions affect translation task performance. The condition targeted in the present study is 'time' which previous literature on cognitive psychology has shown to have influential effects on task performance success. More specifically, the study is interested in the question of whether time pressure influences translation quantity and quality. Translation quality and quality are two important concerns for translation market because, as mentioned before, the market feels pressured to deliver translation products with high qualities as fast as possible (Hermans \& Lambert, 1998; Ørsted, 2001).

\section{Research Questions}

As said above, the present study was set to examine whether time pressure had significant effects on the quality and quantity of translation task performance by Iranian students of Translation Studies. So, the following research questions were formulated to serve this purpose.

Research Question 1: Does time pressure affect the quality with which Iranian students of Translation Studies perform a translation task?

Research Question 2: Does time pressure affect the quantity of translation task performance by Iranian students of Translation Studies?

\section{Research Hypotheses}

To the knowledge of the researchers, the present study is the first to investigate the effects of time pressure on the quality and quantity of translation task performance. In other words, there is no literature background or theoretical models to assume that time pressure influences translation task performance. So, required by the idea that scientific hypotheses should be formulated according to the existence or absence of scientific evidence or theoretical models on the relationships among variables to avoid Type-I and Type-II errors (Bryman, 2015), it was decided to formulate null hypotheses as there is no previous evidence to claim that time pressure would affect translation task performance. The null hypotheses of the study were as the following:

Null Hypothesis 1: Time pressure does not affect the quantity of translation task performance by Iranian students of Translation Studies.

Null Hypothesis 2: Time pressure does not affect the quality with which Iranian students of Translation Studies perform a translation task.

\section{Method}

\subsection{Participants}

The participants of the present study were sampled from two intact classrooms held at the MA level of Translation Studies in a university in Iran. All the participants had Persian as their native language. In addition, the participants studied English as a foreign language for more than 11 years (two years at junior high school, four years at high school, four years at the BA level, and one year at the MA level). The participants' ages ranged from 23 to 31 ( $\mathrm{M}=25.3, \mathrm{SD}=$ 2.6). None of the participants reported visits to countries where English is spoken as a native language. One of the classrooms was randomly assigned as the experimental group $(\mathrm{N}=23)$ and the other classroom was assigned as the control group $(\mathrm{N}=21)$.

\subsection{Translation Excerpt}

The excerpt was sampled from the novel Salvage the Bones, a novel written by Jesmyn Ward in 2011. The novel was selected on the basis of the assumption that it would be less familiar to Iranian readers and, therefore, background knowledge of the plot of the novel would not affect the results. The excerpt to be translated in the present study was sampled from the early chapters of the novel to make sure that the participants would understand the storyline of the novel. The length of the excerpt consisted of about 400 words, a length which was appropriate for serving the purposes of the present study.

\subsection{Procedure}

The following procedure was adopted to collect the data required for the purposes of the present study. First, two intact classes at Islamic Azad University South Tehran Branch were sampled. The classes were held by the same university professor to teach MA-level students on the theories and models of translation. The purposes of the study were explained to the students and the students were informed that their participation in the classroom was optional. Hopefully, all the students in both classrooms agreed to participate in the study. One of the classrooms was randomly chosen as the experimental group and the other classroom was chosen as the control group.

The students in both classrooms were asked to translate the sampled excerpt from the English language into the Persian language. The participants in the control group were allowed free time to translate the excerpt from English into Persian. The participants in the experimental group, on the other hand, were allowed 30 minutes to translate the excerpt. 
The time limit for the experimental group was decided after a pilot study with 6 students of Translation Studies at the MA level. The least time taken to translate the excerpt from English into Persian in the pilot study was set as the time limit for the participants in the experimental group.

To be able to compare the translation performance of the two groups (i.e., control group and experimental group) on a time-constant scale, it was decided to analyze only the first 15 minutes of their translation performance. So, at minute 15 of their performance, the participants were told to mark the extent they have translated from the sampled excerpt in both the source-language text and the target-language text. To make sure that the participants marked their texts appropriately when told to do so, two of the researchers were present on the data collection sessions who walked around the classrooms, checking if the texts were marked.

\subsection{Measures and Scoring}

As mentioned earlier, the present study was set to determine whether time pressure would have effects on the quantity and quality of translation task performance by Iranian students of Translation Studies at the MA level. So, the following two measures were employed to serve the purposes of the study.

Quantity Measure: To calculate how much of the SL text each of the participants had translated, the number of words the participant had been successful to translate from the SL into the TL at 15 minutes was counted.

Quality Measure: To calculate the quality of the translation task performed by each participant, Waddington's (2001) framework for translation quality assessment was utilized. The framework assesses translation quality on 10-point scale (i.e., totally inadequate $=1-2$; inadequate $=3-4$; Adequate $=5-6$; almost completely successful $=7-8$; and successful $=9-10)$.

The scoring of the translation task was conducted by two independent raters (i.e., two of the researchers) to make sure about the reliability of the results. The inter-rater reliability for the quantity measure was calculated to be .99 and the inter-rater reliability for the quality measure was calculated to be .92. These indices show that the participants' translation task performance was rated reliably.

\section{Data Analysis}

\subsection{Descriptive Statistics}

In this section, the descriptive and inferential statistics for the data collected in the present study are reported. Table 1 indicates the descriptive statistics for translation quantity for both the control group and the experimental group. As you can see from the table, the participants in the control group had a mean score of 278.70 and a standard deviation of 23.18 while the participants in the experimental group had a mean score of 326.13 and a standard deviation of 33.41 .

Table 1. Descriptive statistics for translation quantity

\begin{tabular}{lcccc}
\hline Group & Minimum & Maximum & Mean & Standard Deviation \\
\hline Control & 191 & 383 & 278.70 & 23.18 \\
Experimental & 253 & 449 & 326.13 & 33.41 \\
\hline
\end{tabular}

Table 2 indicates the descriptive statistics for translation quality for both the experimental group and the control group. The participants in the control group had a mean score of 6.74 and a standard deviation of 2.11 while the participants in the experimental group had a mean score of 5.43and a standard deviation of 1.82 on the quality measure.

Table 2. Descriptive statistics for translation quality

\begin{tabular}{lcccc}
\hline Group & Minimum & Maximum & Mean & Standard Deviation \\
\hline Control & 4 & 9 & 6.74 & 2.11 \\
Experimental & 3 & 7 & 5.43 & 1.82 \\
\hline
\end{tabular}

The above tables show that the experimental group had a higher mean score on the quantity measure than the control group while the control group had a higher mean on the quality measure than the experimental group. Descriptive statistics, however, does not indicate whether the difference between groups of participants is statistically significant or is the result of random errors (Pallant, 2011). Therefore, it is necessary to run inferential statistics to see whether the differences existing between the control group and the experimental group with respect to the measures of translation quantity and quality were statistically significant.

\subsection{Inferential Statistics}

The analysis showed that the distribution of the collected data on the measure of translation quantity was not statistically normal. Therefore, the non-parametric Mann-Whitney $U$ test was used to compare the experimental and control groups' scores on the quantity measure. Table 3 indicates the results of the Mann-Whitney $U$ test run. As the table indicates, the difference between the two groups on this measure was statistically significant $(U=29068.53$, 
Asymp. Sig. $(2$-tailed $)=.000, p<0.05)$. Therefore, the first hypothesis that their time pressure would not affect the quantity of translation task performance by Iranian students of Translation Studies was statistically rejected.

Table 3. Results of Mann-Whitney $U$ test for translation quantity

\begin{tabular}{ccccc}
\hline & Mean Rank & \multicolumn{2}{c}{ Test Statistic } \\
\hline Control & Experimental & Mann-Whitney U & Asymp. Sig. (2-tailed) \\
\hline 20.19 & 25.43 & 29068.53 & .000 \\
\hline$p<0.05$ & & &
\end{tabular}

The analysis showed that the distribution of the collected data on the measure of translation quality was not also statistically normal. Table 4 indicates the results of the Mann-Whitney $U$ test run. As the table indicates, the difference between the two groups on this measure was statistically significant $(U=2895.65$, Asymp. Sig. $(2$-tailed $)=.001, p<$ $0.05)$. Therefore, the second hypothesis that their time pressure would not affect the quality with which Iranian students of Translation Studies perform a translation task was also statistically rejected.

Table 4. Results of Mann-Whitney $U$ Test for translation quality

\begin{tabular}{ccccc}
\hline & Mean Rank & \multicolumn{2}{c}{ Test Statistic } \\
\hline Control & Experimental & Mann-Whitney $U$ & Asymp. Sig. (2-tailed) \\
\hline 22.18 & 17.44 & 2895.65 & .001 \\
\hline$p<0.05$ & & & &
\end{tabular}

\section{Discussion and Conclusion}

The purpose of the present study was to examine whether conditions of translation task performance (here, time pressure) had influences on translation quantity and quality among Iranian students of Translation Studies. The results of the study indicated that a trade-off between translation quantity and quality would be observed when translators render the SL text into the TL under time-pressured conditions, sacrificing translation quality in favor of translation quantity. The participants who were asked to translate under time pressure translated more of the sampled excerpt than those who performed the translation task under time-free conditions. On the other hand, the latter group of participants delivered translation of higher quality as measured by Waddington's (2001) framework for translation quality assessment. What this shows is that the participants' mental resources have been unequally distributed to different aspect of the translation task. The distribution was influenced by the time conditions under which the translation task had been performed. Such a situation has been previously predicted by the competition model of cognition which hypothesizes that different dimensions of a cognitive task are in constant competition to win over attentional resources and that the competition is highly influenced by the condition in which the task is performed (Ellis, 2006; Potter, Staub, \& O'connor, 2002).

The explanation that translator's mental resources are unequally distributed to different translation aspects when rendering a text from the SL into the TL is also supported by the generalization usually made between simultaneous interpreting and translation. For example, there exists a proposition that working-memory is limited in capacity (Baddeley, 2012) and, thus, there is competition between form and meaning in simultaneous conferences interpreting (Cowan, 2000; Liu, Schallert, \& Carroll, 2004; Mizuno, 2005). Time-pressured translation and conference interpreting are both time-constrained and, therefore, the competition between form and meaning in simultaneous conference interpreting can be, by logic, generalized to the process of translation, which presents itself through the tradeoff between translation quantity and quality. In addition, there is evidence that translation competence is modular in nature (see, for example, Gutt, 2014; Millan-Varela \& Bartrina, 2012). The implication of latter this proposition is that translation processes are independent of each other and that the translator has to optimally distribute his/her attentional resources to the translation modules to serve the purposes set for the translation undertaking.

A rival explanation may be that the participants who performed the translation task under time-pressured conditions might have felt higher levels of translation task anxiety, pushing them to translate the sampled excerpt with a higher speed while negatively affecting the quality of their translation performance. However, we assume that this argument cannot explain the results of the present study. The participants in the present study were informed that their attendance in the study was voluntarily and that their performance on the translation task would not have any consequences for their grades in the classroom. In addition, a short post-experiment interview with some of the participants from both groups revealed that the participants felt relaxed during the experiment as the participants reported low levels of anxiety. Therefore, there is no reason to believe that the participants in the experimental group experienced disturbing level of anxiety while performing the translation task.

\section{Implications and Suggestions for Further Research}

The findings of the study have significant implications for both theory and practice in Translation Studies. Recently, attempts have been made in the field of Translation Studies to investigate the cognitive mechanisms and processes 
involved in translation from language into the other (e.g., Gutt, 2014; O'Brien, 2013; Shreve \& Angelone, 2010). These attempts, however, overlooked the translation conditions that may affect these mechanisms and processes. So, it is hoped that the findings of the study would make its own contributions to our understanding of how the conditions under which a translation task is performed affect translation quantity and quality. A second implication is related to the courses designed to train students on translation skills. The findings of the study indicated that different aspects of translation task performance are differentially influenced by time pressure. So, based on these findings, it is necessary for courses on translation skills to design modular curricula to improve students' translation speed and the quality with which they can deliver translation products.

Research in translation studies is circular in that studies should provide the platform for conducting more investigation so that the conclusions made would be firm and more supportable. Therefore, at the end, some suggestions for further research are presented so that the effects of time pressure on translation task performance can be more studies by other investigators. To begin with, the present study was the first to examine the effects of time pressure on the quality and quantity of translation task performance and, thus, firm conclusions cannot be made based on this single study. Therefore, it is suggested that the present study be replicated in a wide variety of contexts to see whether the findings obtained in this study can be generalized to other populations of translators. Second, the present study only compared 30-minute and time-free conditions for performing translation tasks. It is suggested that future studies investigate tighter or looser time conditions to determine whether translation task performance would differ based on different time conditions allowed to render a text from the SL into the TL. Finally, it is recommended that qualitative phases (e.g., interviews) be included in the designs of future studies in order to delve into the attitudes translators hold towards translation from one language into the other under time-pressured and time-free conditions.

\section{References}

Ausubel, D. P. (1960). The use of advance organizers in the learning and retention of meaningful verbal material. Journal of Educational Psychology, 51(5), 267, doi: http://dx.doi.org/10.1037/h0046669.

Baddeley, A. (2012). Working memory: theories, models, and controversies. Annual Review of Psychology, 63, 1-29, doi: http://dx.doi.org/10.1146/annurev-psych-120710-100422.

Bassnett, S. (2013). Translation studies. London: Routledge.

Boxer, D., \& Cohen, A. D. (Eds.). (2004). Studying speaking to inform second language learning. Clevedon: Multilingual Matters.

Brown, C. (2006). Cognitive psychology. Thousand Oaks, CA: Sage Publications, Inc.

Bryman, A. (2015). Social research methods. Oxford: Oxford university press.

Choi, J., \& Lim, H. O. (2000). An overview of the Korean translation market. Meta, 45(2), 383-392, doi: http://dx.doi.org/10.7202/002235ar

Chomsky, N. (1965). Aspects of the theory of syntax. Cambridge, MA: MIT press.

Cowan, N. (2000). Processing limits of selective attention and working memory: Potential implications for interpreting. Interpreting, 5(2), 117-146, doi: http://dx.doi.org/10.1075/intp.5.2.05cow.

Danks, J. H. (1997). Cognitive processes in translation and interpreting. Thousand Oaks, CA: Sage Publications, Inc.

Ellis, N. C. (2006). Selective attention and transfer phenomena in L2 acquisition: Contingency, cue competition, salience, interference, overshadowing, blocking, and perceptual learning. Applied Linguistics, 27(2), 164-194.

Ertmer, P. A., \& Newby, T. J. (1993). Behaviorism, cognitivism, constructivism: Comparing critical features from an instructional design perspective. Performance Improvement Quarterly, 6(4), 50-72, doi: http://dx.doi.org/10.1111/j.1937-8327.1993.tb00605.x.

Eysenck, M. W., \& Calvo, M. G. (1992). Anxiety and performance: The processing efficiency theory. Cognition \& Emotion, 6(6), 409-434, doi: http://dx.doi.org/10.1080/02699939208409696.

Eysenck, M. W., \& Keane, M. T. (2000). Cognitive psychology: A student's handbook (4 ${ }^{\text {th }}$ ed.). London: Routledge.

Guida, F.V., Ludlow, L., \& Wilson, M. (1985). The Meditative effect of time-on task on the academic anxiety/achievement interaction: A structure model. Journal of Research and Development in Education 19. (1), 21-26.

Gutt, E. A. (2014). Translation and relevance: Cognition and context. London: Routledge.

Halverson, S. (2003). The cognitive basis of translation universals. Target, 15(2), 197-241, doi: http://dx.doi.org/10.1075/target.15.2.02hal.

Harrison, D. A., Price, K. H., Gavin, J. H., \& Florey, A. T. (2002). Time, teams, and task performance: Changing effects of surface-and deep-level diversity on group functioning. Academy of management journal, 45(5), 1029-1045, doi: http://dx.doi.org/10.2307/3069328.

Hermans, J., \& Lambert, J. (1998). From translation markets to language management: The implications of translation services. Target, 10(1), 113-132, doi: http://dx.doi.org/10.1075/target.10.1.06her. 
Hubscher-Davidson, S. E. (2009). Personal diversity and diverse personalities in translation: A study of individual differences. Perspectives: Studies in Translatology, 17(3), 175-192, doi:http://dx.doi.org/10.1080/09076760903249380.

Kahn, W. A. (1990). Psychological conditions of personal engagement and disengagement at work. Academy of Management Journal, 33(4), 692-724, doi: http://dx.doi.org/10.2307/256287.

Kuhiwczak, P., \& Littau, K. (2007). A companion to translation studies. Clevedon: Multilingual Matters.

Labelle, M. A., Graf, P., Grondin, S., \& Gagne-Roy, L. (2009). Time-related processes in time-based prospective memory and in time-interval production. European Journal of Cognitive Psychology, 21(4), 501-521, doi: http://dx.doi.org/10.1080/09541440802031000.

Liu, M., Schallert, D. L., \& Carroll, P. J. (2004). Working memory and expertise in simultaneous interpreting. Interpreting, 6(1), 19-42, doi: http://dx.doi.org/10.1075/intp.6.1.04liu.

Mehnert, U. (1998). The effects of different lengths of time for planning on second language performance. Studies in Second Language Acquisition, 20(1), 83-108, doi: http://dx.doi.org/10.1017/S0272263198001041.

Millan-Varela, C., \& Bartrina, F. (2012). The Routledge handbook of translation studies. London: Routledge.

Mizuno, A. (2005). Process model for simultaneous interpreting and working memory. Meta, 50(2), 739-752, doi: http://dx.doi.org/10.7202/011015ar.

Munday, J. (2016). Introducing translation studies: Theories and applications. London: Routledge.

Novak, J. D. (2010). Learning, creating, and using knowledge: Concept maps as facilitative tools in schools and corporations. London: Routledge.

O'Brien, S. (2013). The borrowers: Researching the cognitive aspects of translation. Target, 25(1), 5-17, doi: http://dx.doi.org/10.1075/target.25.1.02obr.

Ørsted, J. (2001). Quality and efficiency: Incompatible elements in Translation Practice? Meta, 46(2), 438-447, doi: http://dx.doi.org/10.7202/003766ar.

Pallant, J. (2011). SPSS survival manual: A step-by-step guide to data analysis using SPSS (4 ${ }^{\text {th }}$ ed.). Nova Iorque: McGraw Hill.

Potter, M. C., Staub, A., \& O'connor, D. H. (2002). The time course of competition for attention: attention is initially labile. Journal of Experimental Psychology: Human Perception and Performance, 28(5), 1149-1162.

Saks, A. M. (2006). Antecedents and consequences of employee engagement. Journal of Managerial Psychology, 21(7), 600-619, doi: http://dx.doi.org/10.1108/02683940610690169.

Shao, Z., Roelofs, A., Martin, R. C., \& Meyer, A. S. (2015). Selective inhibition and naming performance in semantic blocking, picture-word interference, and color-word Stroop tasks. Journal of Experimental Psychology: Learning, Memory, and Cognition, 41(6), 1806-1820, doi: http://dx.doi.org/10.1037/a0039363.

Shreve, G. M., \& Angelone, E. (Eds.). (2010). Translation and cognition. Amsterdam: John Benjamins Publishing, doi: http://dx.doi.org/10.1075/ata.xv.

Waddington, C. (2001). Different methods of evaluating student translations: The question of validity. Meta, 46(2), 311-325, doi: http://dx.doi.org/10.7202/004583ar.

Xuanmin, L. (2003). A textual-cognitive model for translation. Perspectives: Studies in Translatology, 11(1), 73-79, doi: http://dx.doi.org/10.1080/0907676X.2003.9961464.

Zheng, B., \& Xiang, X. (2014). The impact of cultural background knowledge in the processing of metaphorical expressions: An empirical study of English-Chinese sight translation. Translation and Interpreting Studies, 9(1), 5-24, doi: http://dx.doi.org/10.1075/tis.9.1.01zhe. 